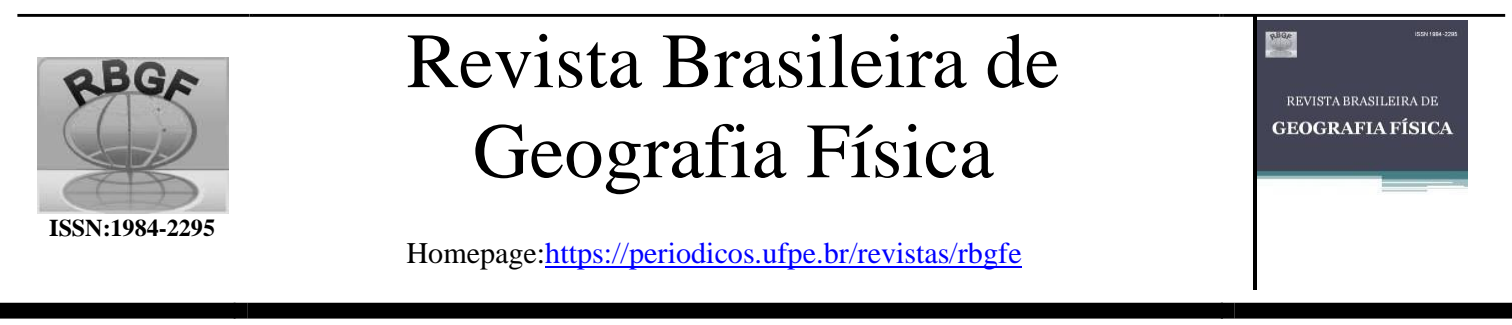

\title{
Bioma Cerrado: fragilidades e potencialidades socioambientais de um projeto de trilha no Parque Nacional Serra da Canastra
}

\begin{abstract}
Ana Luiza de Souza Marcondes ${ }^{1}$, Daniela Rocha Teixeira Riondet-Costa ${ }^{2}$, Gabriel de Oliveira Machado ${ }^{3}$, Gabriel Wilson Lorena Florêncio ${ }^{4}$, Guilherme Prado Alves ${ }^{5}$, Janine Ameku Neves ${ }^{6}$, Kleber Barcelar Santos ${ }^{7}$, Michel Yasuyuki Gejima Junior ${ }^{8}$, Natália Barbosa Fernades ${ }^{9}$ Nívea Adriana Dias Pons ${ }^{10}$, Rafael Bitencourt Benassi ${ }^{11}$.

1,3,4,7,8,11 Universidade Federal de Itajubá - UNIFEI, Campus Itajubá. Discente do Programa de Pós-Graduação em Meio Ambiente e Recursos Hídricos - POSMARH. Avenida BPS, 1303, Pinheirinho, Itajubá/MG. ${ }^{5,9}$ Universidade Federal de Itajubá - UNIFEI, Campus Itajubá. Discente do Programa de Pós-Graduação em Desenvolvimento, Tecnologias e Sociedade - PPG DTecS. Avenida BPS, 1303, Pinheirinho, Itajubá/MG. ${ }^{2,10}$ Universidade Federal de Itajubá - UNIFEI, Campus Itajubá. Docente do Programa de Pós-Graduação em Meio Ambiente e Recursos Hídricos - POSMARH. Avenida BPS, 1303, Pinheirinho, Itajubá/MG. ${ }^{6}$ Universidade Federal de Alfenas UNIFAL, Campus Alfenas. Discente do Programa de Pós-Graduação em Ciências Ambientais - PPGCA. Rua Gabriel Monteiro da Silva, 700, Alfenas/MG.
\end{abstract}

Artigo recebido em 23/02/2020 e aceito em 13/12/2020

\section{R E S UMO}

O ecoturismo é uma das atividades mais desenvolvidas em Parques Nacionais. A implementação de trilhas eco turísticas pode funcionar como atrativo turístico e favorecer empreendimentos locais, entretanto, podem causar impactos negativos diretos ao meio ambiente. Esses impactos podem ser minimizados através de estudos prévios para verificação de viabilidade na implementação das trilhas. Sendo assim, o objetivo deste trabalho foi apontar fragilidades e potencialidades socioambientais de um projeto de trilha para o uso turístico no Parque Nacional Serra da Canastra (PNSC), localizado no sudoeste de Minas Gerais, no bioma Cerrado. Para tanto, a partir de análise multicritério no software ArcGIS, foram elaborados os mapas de suscetibilidade à erosão e aptidão ao uso do turístico do entorno da trilha. A análise final foi realizada por meio da Matriz SWOT, que permitiu sintetizar as fragilidades e potencialidades socioambientais, evidenciando as forças e fraquezas ( situação presente) e as oportunidades e ameaças (situação futura, caso a proposta de trilha seja efetivada). Os resultados mostram que mais de $80 \%$ da área estudada possui alta e muito alta aptidão ao ecoturismo, sendo suas principais potencialidades a proximidade a recursos hídricos e a estradas de acesso, a predominância de declividade moderada (3-8\%) e a possibilidade de desenvolvimento do turismo local e de atividades de sensibilização ambiental. Por outro lado, as principais fragilidades apontaram para a ameaça de compactação do solo, a evasão de espécies endêmicas e o relevo escarpado encontrado em um trecho da trilha, mostrando que pequenas alterações no trajeto tornam viável a implementação da trilha proposta.

Palavras-chave: Áreas protegidas, trilha de parque, ecoturismo, análise SWOT.

\section{Cerrado Biome: social-environmental weaknesses and potentialities of a trail project in the Serra da Canastra National Park}

\begin{abstract}
Ecotourism is one of the most developed activities in National Parks. The implementation of eco-tourism trails can act as tourist attraction and favor local enterprises, however, they can cause direct negative impacts on the environment. These impacts can be minimized through previous studies to verify the feasibility of implementing the trails. Therefore, the objective of this work was to point out socio-environmental weaknesses and potentialities of a trail project for tourist use in the Serra da Canastra National Park (PNSC), located in the southwest of Minas Gerais, in the Cerrado biome. For that, using multicriteria analysis in the ArcGIS software, maps of susceptibility to erosion and aptitude for tourism use around the trail were elaborated. The final analysis was carried out using the SWOT Analysis, which made it possible to summarize the socio-environmental weaknesses and potentialities, highlighting the strengths and weaknesses (present situation) and opportunities and threats (future situation, if the proposed trail is implemented). The results show that more than $80 \%$ of the
\end{abstract}


studied area has high and very high aptitude for ecotourism, its main potential being the proximity to water resources and access roads, the predominance of moderate declivity (3-8\%) and the possibility of development of local tourism and environmental awareness activities. On the other hand, the main weaknesses pointed to the threat of soil compaction, the evasion of endemic species and the rugged relief found in a stretch of the trail, showing that small changes in the path make the implementation of the proposed trail viable.

Keywords: Protected areas; park trail; ecotourism; SWOT analysis.

\section{Introdução}

O Cerrado brasileiro é o segundo maior bioma da América Latina (Sano et al., 2019), a savana mais rica do mundo e um dos 25 hotspots mundiais com grande concentração de espécies endêmicas e em extinção (Myers et al., 2000; Klink e Machado, 2005; Freitas et al., 2019). Dos seus $1.783 .200 \mathrm{~km}^{2}$ de extensão original restam apenas $20 \%$, sendo 6,2\% de áreas protegidas (Myers et al., 2000; Françoso et al., 2015). Ainda, estimativas indicam que o desmatamento do cerrado avança cerca de $0,7 \%$ ao ano, o que é considerado um índice alarmante, representando uma perda anual em torno de três milhões de hectares (Adarme et al., 2020; Guerra et al., 2020).

O Brasil possui como áreas protegidas as Áreas de Preservação Permanente (APP), as Reservas Legais (RL), a Servidão Ambiental e as Unidades de Conservação (UC). Estas últimas são internacionalmente conhecidas como áreas protegidas, de acordo com a categorização da International Union for Conservation of Nature (IUCN) (Araujo, 2007; Riondet-Costa, 2013). As UCs são ferramentas importantes na preservação da diversidade das espécies e integridade do habitat, assim como, para as funções dos ecossistemas, mitigação dos efeitos de mudanças climáticas e manutenção dos recursos naturais de modo menos alterado possível (Myers et al., 2000; Brooks, Fonseca e Rodrigues, 2004; Araujo, 2007; Lemes e Loyola; 2014; Rodrigues et al., 2015; Xu et al., 2017).

A criação das UCs busca preservar a oferta dos serviços ecossistêmicos essenciais ao homem, entre eles os serviços de provisão (água, madeira, frutos), de regulação (estoque de carbono, qualidade do ar), de suporte (formação dos solos, biodiversidade) e os serviços culturais (beleza cênica, ecoturismo e recreação) (Locatelli. Imbach e Wunder, 2013; Resende, 2018; Hummel et al., 2019). Portanto, são reconhecidas como uma das políticas públicas mais utilizadas na redução dos índices de desmatamento e, consequentemente, na proteção da biodiversidade (Muruthi, 2006; Prates e Azevedo, 2015).
As UCs são instituídas pelo governo federal, estadual ou municipal e, conforme o Sistema Nacional de Unidades de Conservação SNUC (Lei n ${ }^{\circ} 9.985 / 2000$ ), podem ser de proteção integral ou de uso sustentável, sendo distribuídas em doze categorias (Brasil, 2000). Do grupo das UCs de proteção integral, o Parque Nacional é uma das categorias mais conhecidas pela população em geral. Esse grupo tem como objetivo preservar a natureza e garantir a manutenção dos ecossistemas naturais com grande relevância ecológica e beleza cênica, ou seja, mantê-los livre de alterações causadas por interferência humana, com gestão territorial e racionalização ao uso (Brasil, 2000; Antunes, 2012; Silva, 2015). Nesses territórios é possível a realização de pesquisas científicas e o desenvolvimento de atividades de educação ambiental, de recreação e de turismo ecológico, porém, tais atividades estão sujeitas às normas $\mathrm{e}$ restrições estabelecidas no Plano de Manejo da UC e às normas estabelecidas pelo órgão gestor em conformidade com o SNUC (Nascimento et al., 2016; Neto, Whitaker e Vasconcelos, 2018).

O Plano de Manejo é um dos vários instrumentos disponíveis à gestão territorial das UCs. Nele são estabelecidos o zoneamento e as normas que presidem o uso da área, além do manejo dos recursos naturais, incluindo a implantação das estruturas físicas necessárias à gestão e uso público da unidade (Brasil, 2000; Manetta et al., 2015; Giovanelli et al., 2016). Este instrumento é dinâmico e prático, pois se fundamenta na análise de fatores ambientais e socioeconômicos e oferece orientações nas dimensões do espaço (onde), do tempo (quando) e do método (como) (Muruthi, 2006; Giovanelli et al., 2016; Neto, Whitaker e Vasconcelos, 2018).

O turismo, a recreação e o lazer são atividades de uso público em algumas das UCs de proteção integral, sendo o ecoturismo o mais popularmente visado. $\mathrm{O}$ ecoturismo pode ser definido como um segmento da atividade turística que utiliza o patrimônio natural e cultural de forma sustentável e incentiva sua conservação, buscando a sensibilização ambiental por meio da interpretação do ambiente (Brasil, 2000; Filetto e Macedo, 2015; Reis e Queiroz, 2017; Freire e 
Almeida, 2018). O ecoturismo dentro de uma UC proporciona benefícios econômicos diretos para as comunidades próximas às áreas protegidas por meio da criação de empregos e prestação de serviços, o que contribui com a própria gestão das UCs por promover maior geração de renda, economia independente e visibilidade (Vallejo, 2013; Balmford et al., 2015; Canto-Silva e Silva, 2017; Cunha, Nóbrega e Kerlei, 2017; Souza et al., 2017). A implementação desse instrumento apresenta resultados positivos em diversos países e exige um estudo detalhado dos impactos socioambientais e econômicos, permitindo assim o controle e a redução dos impactos que a visitação pode causar (Huhtala, Kajala e Vatanen, 2010; Lobo e Simão, 2011; Mihalic, 2016; Cullinane e Koontz, 2016; Oliveira, 2019).

Pensando na minimização destes impactos, a integração da gestão da UC e as ações educativas são eficientes ferramentas na redução de comportamentos que impactam de forma negativa a integridade dos parques nacionais, como por exemplo, as caminhadas fora da trilha (Hockett, Marion e Leung, 2017).

As trilhas são um instrumento de preservação, de apreciação e de educação ambiental e, também, uma das formas de controlar a visitação (Hesselbarth, Vachowsski e Davies, 2009). Também são um dos tipos de infraestrutura mais importantes em áreas naturais protegidas, visto que elas são projetadas para facilitar o acesso do visitante aos atrativos turísticos (Tomczyk e Ewertowski, 2013). Entretanto, a falta de planejamento e monitoramento pode conduzir a situações conflitantes com os propósitos das UCs, causando impactos negativos ao meio físico (Almeida, 2014, Rocha et al., 2018).

Nesse contexto, o uso das geotecnologias como o Sensoriamento Remoto (SR) e o Sistema de Informações Geográficas (SIG) é de fundamental importância para o planejamento, monitoramento e manejo do uso público em áreas protegidas (Santos et al., 2017; Andrade, Melo e Silva 2019), especialmente em trilhas (Oliveira et al., 2014). A realização de estudos envolvendo o mapeamento dessas áreas torna-se, portanto, uma ferramenta útil para evitar potenciais impactos, por sua eficiência em auxiliar a gestão e tomada de decisão, facilitando assim em um delineamento mais fidedigno da região, além de uma caracterização mais satisfatória da ecorregião (Sano et al., 2019).
O bioma Cerrado é conhecido por sua fragilidade natural, estando suscetível a incêndios e ravinamentos, que podem ser intensificados pela ação antrópica, como a expansão para o uso agrícola e o turismo indiscriminado (Messias e Ferreira, 2017; Rodrigues e Collares, 2017; Gonçalves, Meneguzzo e Moro, 2019). Apesar da existência de diversos estudos envolvendo as fragilidades do bioma, estudos voltados para os impactos das trilhas turísticas no Cerrado ainda são escassos.

Considerando o grande apelo turístico do bioma e o incentivo para desenvolvimento de turismo ecológico em Parques Nacionais, faz-se de extrema importância que os impactos ambientais e sociais das trilhas sejam analisados antes da efetiva implementação e abertura das mesmas para o público em geral, possibilitando assim melhorias no traçado, além da identificação de pontos críticos que possam necessitar de maior atenção e sinalização antes de que os impactos de fato ocorram. (Rangel, Botelho e Machado, 2017; Teixeira e Michelin, 2017).

Diante desses aspectos, o objetivo deste estudo foi analisar as fragilidades e potencialidades socioambientais de um projeto de trilha para o uso turístico no Parque Nacional da Serra da Canastra (PNSC), UC localizada no sudoeste de Minas Gerais, no bioma Cerrado. Como hipótese inicial têm-se que a implementação da trilha pode ser oportuna para o desenvolvimento de ações de sensibilização ambiental, além de favorecer o turismo local, mas que a declividade da área e a possibilidade de intensificação dos processos erosivos podem ser empecilhos para a sua devida implementação.

\section{Material e métodos}

Área de estudo

O PNSC é uma UC de proteção integral, localizado dentro dos limites de 06 (seis) municípios (Figura 1), sendo eles: Capitólio $(5,01 \%)$, Delfinópolis $(28,04 \%)$, Sacramento (3,76\%), São João Batista do Glória (13,18\%), São Roque de Minas (43,21\%) e Vargem Bonita $(6,8 \%)$. Criado em 3 de abril de 1972 pelo decreto $\mathrm{n}^{\mathrm{o}} 70.355$, abrange aproximadamente 200.000 hectares pertencente ao bioma do Cerrado sob a gerência executiva do Instituto Chico Mendes de Conservação da Biodiversidade (ICMBIO). A 
localização do PNSC pode ser visualizada na Figura 1.

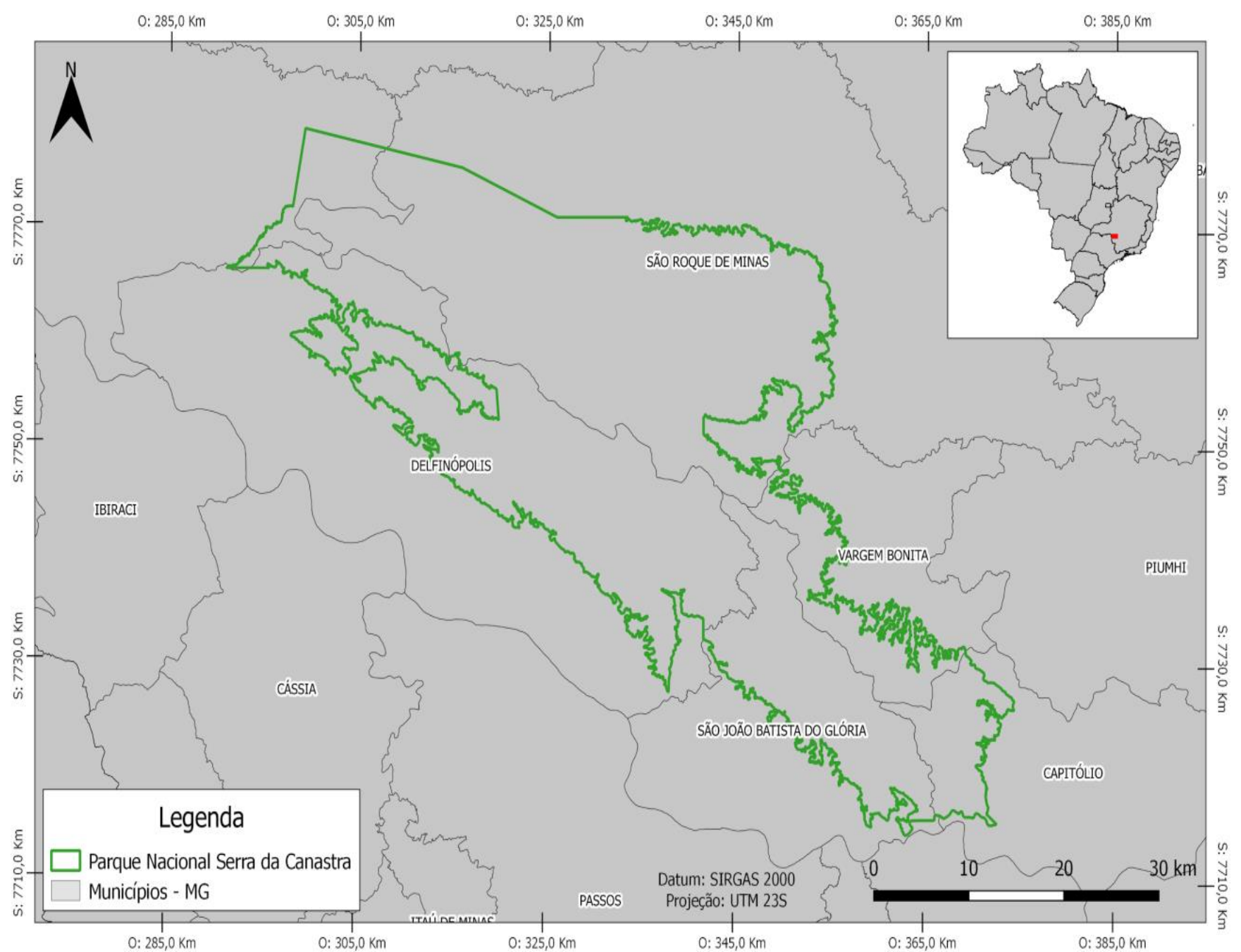

Figura 1. Localização do Parque Nacional Serra da Canastra.

Coleta de dados

A coleta de dados partiu do projeto da trilha previamente mapeada pela equipe técnica do PNSC, utilizando-se o Google Earth, de onde se obteve os vetores da estrada e da trilha. Também foram utilizadas imagens de satélite, dados de solo, vegetação e o modelo digital do terreno. Tais informações foram levantadas a partir dos bancos de dados pré-existentes, que geraram mapas primários. Os mapas secundários foram gerados por meio da análise de multicritério, realizada no software QGis versão 3.4.12. A Figura 2 ilustra o procedimento metodológico utilizado na pesquisa. 


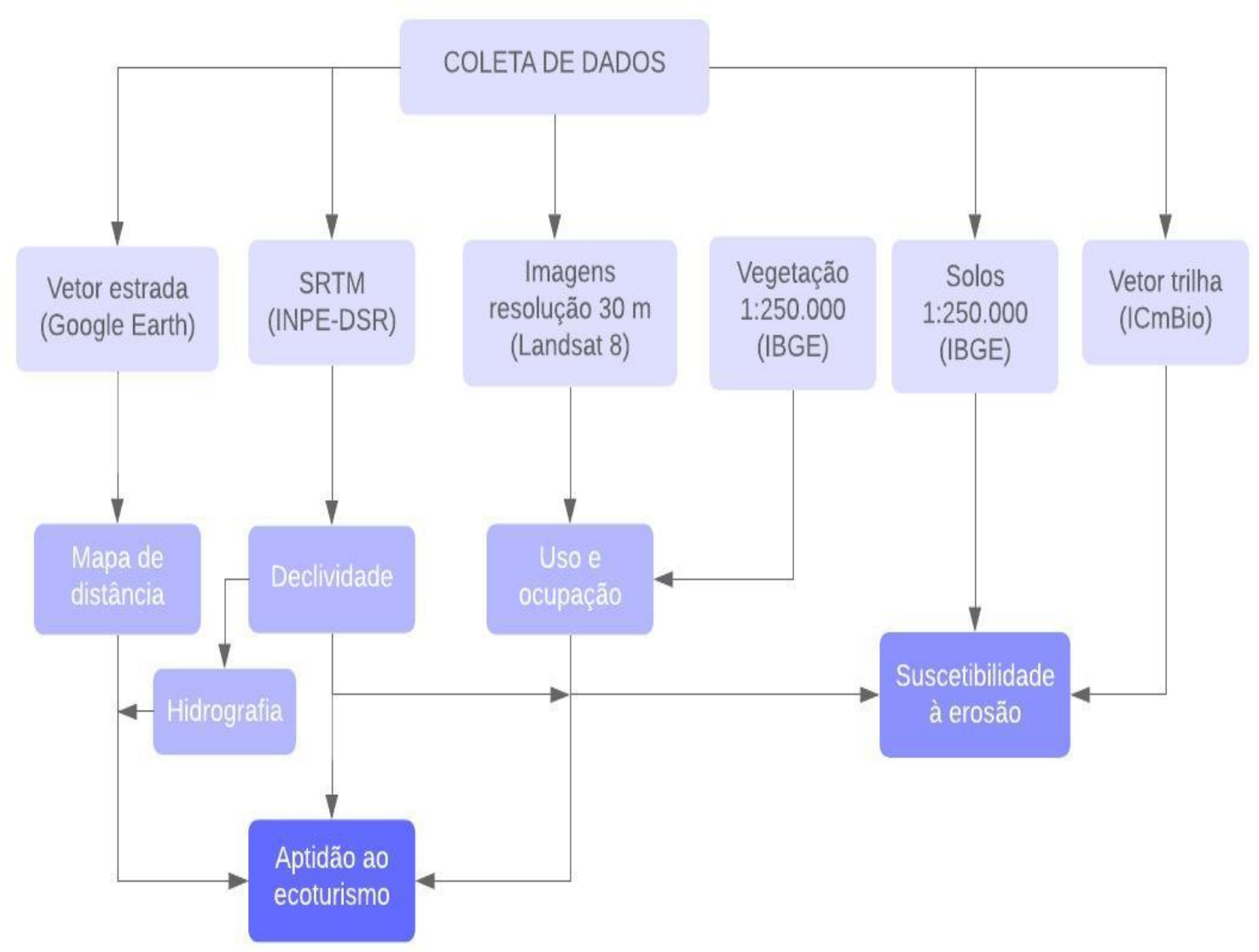

Figura 2. Fluxograma de materiais coletados e mapas secundários gerados.

Os fatores de ponderação para a elaboração dos mapas de suscetibilidade à erosão e de aptidão ao uso turístico da trilha foram adotados com base em levantamento bibliográfico. As categorias avaliadas foram: o tipo de solo, drenagem, a declividade e o uso e cobertura do solo, que influenciam a visitação pública e a tendência a erodir.

A partir do vetor do traçado da trilha, foi delimitado um buffer com extensão de $1 \mathrm{~km}$, sendo esta porção do parque denominada de entorno da área de estudo deste trabalho.

Os vetores das estradas existentes dentro do parque não estavam documentados, portanto foi necessário traçá-las no software Google Earth. A partir desses vetores, foi elaborado o mapa de distâncias das estradas: 0-200 m, 201-400 m, 401$600 \mathrm{~m}, 601-800 \mathrm{~m}, 801-1000 \mathrm{~m}$.

O Modelo Digital de Elevação proveniente da Missão Topográfica Radar Shuttle (acrônimo em inglês SRTM) foi utilizado para elaboração da carta de declividade e para o traçado das drenagens existentes dentro do parque, este último, com o uso das ferramentas de cálculo de parâmetros hidrológicos do software QGis versão 3.4.12.

A partir das bandas 2 a 7 da imagem do satélite Landsat 8 foi utilizada a ferramenta SemiAutomatic Classification Plugin (SCP) do QGis versão 3.4.12 para a classificação da imagem e elaboração do mapa de uso e ocupação do solo. As classes identificadas foram: solo exposto, vegetação rasteira, vegetação arbórea, sombra e afloramento rochoso. É importante destacar a limitação da imagem de satélite, pois a resolução espacial de $30 \mathrm{~m}$ da imagem do Landsat 8 não permite maior detalhamento.

Para a elaboração do mapa de susceptibilidade à erosão, foram considerados os fatores declividade, pedologia e uso e ocupação do solo, combinados através da técnica de análise multicritério. Com base nas ponderações adotadas por Crepani et al. (2001) e Montaño (2002), e na realidade do bioma, foram considerados os pesos descritos na Tabela 1. Considerou-se que para maiores declividades, há uma maior probabilidade de ocorrência dos processos erosivos, bem como 
para solos expostos e cobertura vegetal rasteira (Trindade e Rodrigues, 2016; Guerra et al., 2017). Quanto à pedologia, devido à sua composição, os neossolos e cambissolos são mais suscetíveis aos desgastes físicos do solo (Saraiva, Silva e Santos 2016).

Tabela 1. Fatores de influência, peso atribuído de acordo com a classe e a influência na erosão do solo.

\begin{tabular}{|c|c|c|c|}
\hline Fator & Classe & Peso & $\begin{array}{l}\text { Influência } \\
\text { geral (\%) }\end{array}$ \\
\hline \multirow{6}{*}{ Declividade } & $0-3 \%$ & 1 & \multirow{6}{*}{30} \\
\hline & $3-8 \%$ & 2 & \\
\hline & $8-20 \%$ & 4 & \\
\hline & $20-45 \%$ & 6 & \\
\hline & $45-75 \%$ & 8 & \\
\hline & $>75 \%$ & 9 & \\
\hline \multirow{3}{*}{ Pedologia } & Cambissolo & 7 & \multirow{3}{*}{50} \\
\hline & $\begin{array}{l}\text { Latossolo } \\
\text { vermelho }\end{array}$ & 2 & \\
\hline & Neossolo & 9 & \\
\hline \multirow{5}{*}{$\begin{array}{c}\text { Uso e } \\
\text { ocupação do } \\
\text { solo }\end{array}$} & $\begin{array}{l}\text { Afloramento } \\
\text { rochoso }\end{array}$ & 1 & \multirow{5}{*}{20} \\
\hline & Solo exposto & 9 & \\
\hline & $\begin{array}{l}\text { Vegetação } \\
\text { rasteira }\end{array}$ & 5 & \\
\hline & $\begin{array}{l}\text { Vegetação } \\
\text { arbórea }\end{array}$ & 2 & \\
\hline & Sombra & 1 & \\
\hline
\end{tabular}

Para a elaboração do mapa de aptidão ao uso turístico da trilha, atribuiu-se um peso maior para fatores que favorecem o uso turístico. Foram considerados os fatores declividade, distância das estradas, distância dos rios e uso e ocupação do solo, também ponderados através da técnica de análise multicritério, exposta na tabela 2. Quanto à declividade, considerou-se que os terrenos mais planos proporcionam menor desgaste físico ao pedestre. A presença de vegetação arbórea foi definida como uma potencialidade ao turismo, enquanto que a proximidade das estradas proporciona maior segurança e acesso de pessoas com mobilidade reduzida (Oliveira, Barros e
Buchianeri, 2008). Quanto à distância das drenagens, considerou-se que a maior proximidade com os corpos d'água pode oferecer riscos para a qualidade dos mesmos, e uma distância elevada prejudica o potencial turístico da área. Deste modo, considerou-se a distância de 300 metros como ideal para o uso turístico. Tais fatores podem ser apreciados na Tabela 2.

Tabela 2. Fatores de influência, peso atribuído de acordo com a classe e influência na aptidão ao uso turístico.

\begin{tabular}{|c|c|c|c|}
\hline Fator & Classe & Peso & $\begin{array}{l}\text { Influência } \\
\text { geral }(\%)\end{array}$ \\
\hline \multirow{6}{*}{ Declividade } & $0-3 \%$ & 9 & \multirow{6}{*}{40} \\
\hline & $3-8 \%$ & 8 & \\
\hline & $8-20 \%$ & 6 & \\
\hline & $20-45 \%$ & 4 & \\
\hline & $45-75 \%$ & 2 & \\
\hline & $>75 \%$ & 1 & \\
\hline \multirow{4}{*}{$\begin{array}{c}\text { Distância de } \\
\text { estradas }\end{array}$} & $0-200 \mathrm{~m}$ & 9 & \multirow{4}{*}{20} \\
\hline & $201-400 \mathrm{~m}$ & 7 & \\
\hline & $401-600 m$ & 5 & \\
\hline & $\begin{array}{c}601-800 m \\
801-1000 m\end{array}$ & $\begin{array}{l}3 \\
1\end{array}$ & \\
\hline \multirow{5}{*}{$\begin{array}{l}\text { Uso e ocupação } \\
\text { do solo }\end{array}$} & $\begin{array}{l}\text { Afloramento } \\
\text { rochoso }\end{array}$ & 3 & \multirow{5}{*}{20} \\
\hline & Solo exposto & 2 & \\
\hline & $\begin{array}{l}\text { Vegetação } \\
\text { rasteira }\end{array}$ & 8 & \\
\hline & $\begin{array}{l}\text { Vegetação } \\
\text { arbórea }\end{array}$ & 9 & \\
\hline & Sombra & 1 & \\
\hline \multirow{6}{*}{$\begin{array}{l}\text { Distância dos } \\
\text { rios }\end{array}$} & $0-100 \mathrm{~m}$ & 3 & \multirow{6}{*}{20} \\
\hline & $101-200 \mathrm{~m}$ & 5 & \\
\hline & $201-300 \mathrm{~m}$ & 7 & \\
\hline & $301-400 \mathrm{~m}$ & 5 & \\
\hline & $401-500 \mathrm{~m}$ & 3 & \\
\hline & $>500 \mathrm{~m}$ & 1 & \\
\hline
\end{tabular}

Análise dos dados 
Para identificar os pontos fortes e as oportunidades (potencialidades) e os pontos fracos e ameaças (fragilidades) relacionadas ao uso e aptidão ao turismo da trilha, a análise SWOT (FOFA, em português, significando: Forças, Oportunidades, Fraquezas e Ameaças) foi adaptada na concepção do planejamento de conservação, considerando as perspectivas ecológica e social (Scollozi et al., 2014).

A SWOT proposta fornece informações úteis para analisar as fragilidades e potencialidades levantadas, a fim de garantir a conservação da biodiversidade e o uso turístico. É um importante método analítico usado para quantificar as forças competitivas e formular as melhores estratégias de gerenciamento e desenvolvimento (Chang e Huang, 2006; Fiagbomeh e Burger-Arndt, 2015).

A partir das informações geradas por meio do mapeamento da aptidão ao ecoturismo e das localidades suscetíveis à erosão, os gestores podem aproveitar as oportunidades da UC e evitar ameaças. Os mapas de suscetibilidade à erosão e aptidão ao uso turístico serão discutidos a seguir, de modo a se avaliar a adequação da trilha proposta quanto à minimização do impacto ambiental gerado e a segurança dos turistas.

\section{Resultados e discussão}

Levando-se em consideração os fatores supracitados na Tabela 1, foi elaborado o mapa de suscetibilidade à erosão considerando-se um buffer de $1 \mathrm{~km}$ em torno do traçado proposto da trilha (Figura 3).

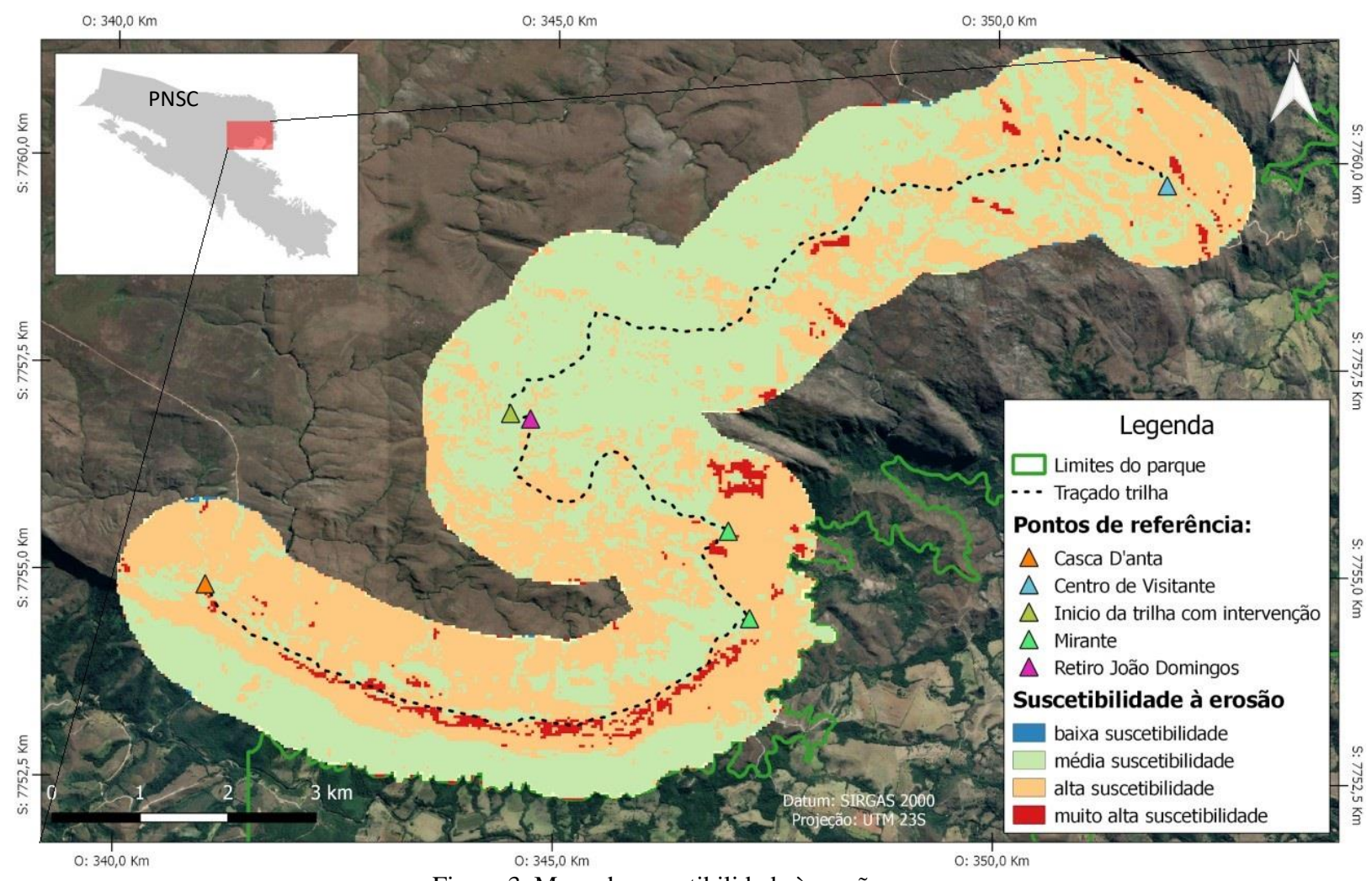

Figura 3. Mapa de suscetibilidade à erosão.

As áreas de cada classe de suscetibilidade à erosão foram calculadas no software QGis, e são apresentadas na Tabela 3.

Tabela 3. Áreas de cada classe de suscetibilidade à erosão

\begin{tabular}{|c|c|c|}
\hline $\begin{array}{c}\text { Classe de } \\
\text { suscetibilidade à erosão }\end{array}$ & $\begin{array}{c}\text { Área } \\
\left(\mathbf{k m}^{2}\right)\end{array}$ & $\begin{array}{c}\text { Porcentagem da } \\
\text { área }\end{array}$ \\
\hline
\end{tabular}

\begin{tabular}{|c|c|c|} 
Baixa suscetibilidade & 0,015 & $0,03 \%$ \\
\hline Média suscetibilidade & 22,28 & $50,49 \%$ \\
\hline Alta suscetibilidade & 20,81 & $47,16 \%$ \\
\hline Muito alta suscetibilidade & 1,02 & $2,31 \%$ \\
\hline Total & $\mathbf{4 4 , 1 3}$ & $\mathbf{1 0 0 , 0 0 \%}$ \\
\hline
\end{tabular}


Pode-se observar que a maior parte da trilha e do entorno tem média $(50,49 \%)$ e alta $(47,16 \%)$ susceptibilidade à erosão. Este fato pode estar atrelado à pedologia, pois áreas com alta susceptibilidade à erosão estão localizadas nos solos predominantes da classe Neossolo. Este tipo de solo é raso, possui limitações de fertilidade e apresenta alta erodibilidade (Saraiva, Silva e dos Santos, 2016; Cuiabano et al., 2017). É possível observar que, a partir do segundo mirante, existem cerca de $7 \mathrm{~km}$ da área com susceptibilidade muito alta à erosão. Isso ocorre principalmente em função da alta declividade (acima de 75\%) predominantemente encontrada nesse trecho devido à presença do relevo escarpado.

Com relação ao uso turístico foi elaborado o mapa de aptidão, apresentado pela Figura 4.

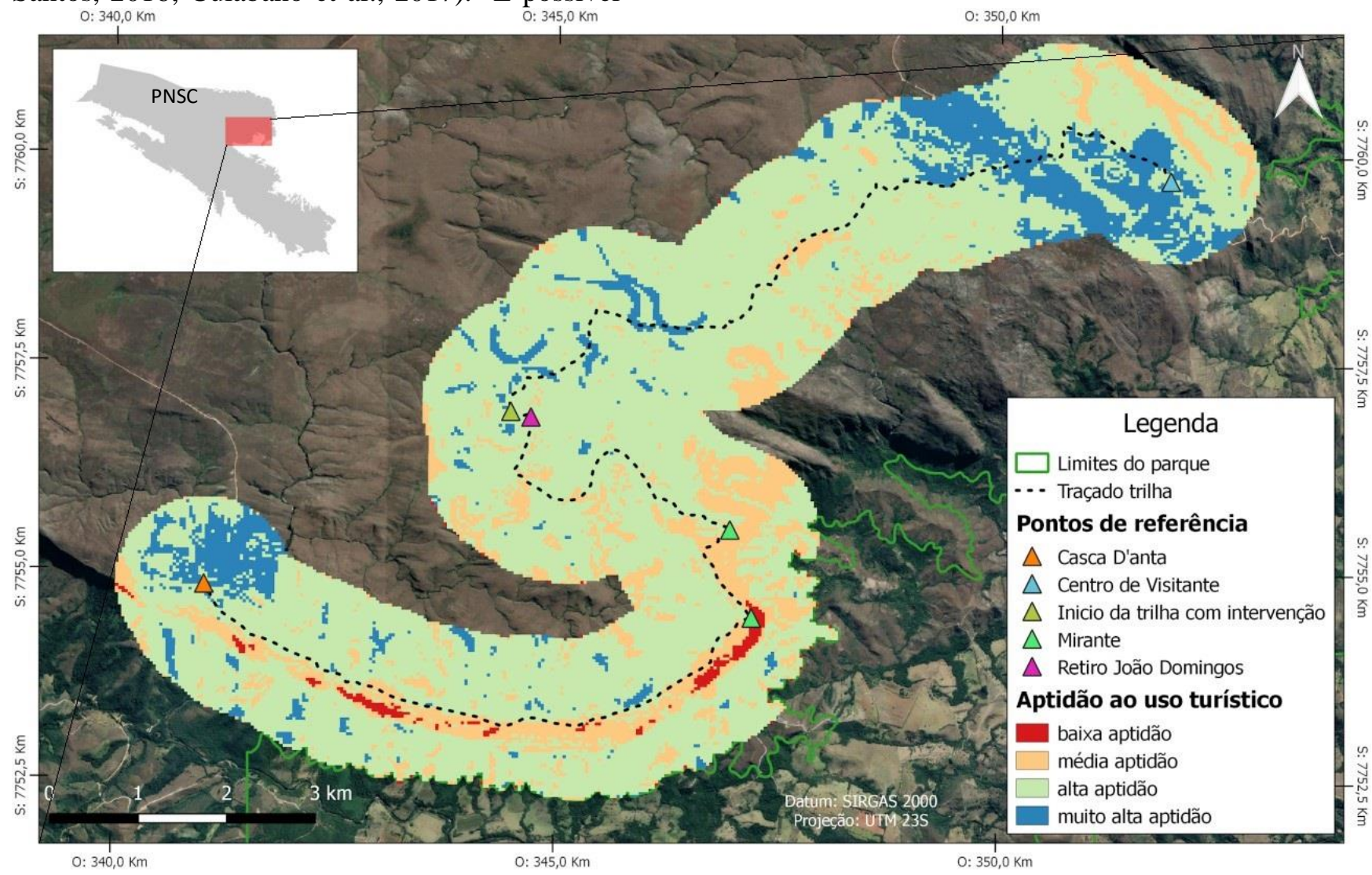

Figura 4. Mapa de aptidão ao uso turístico.

As áreas de cada classe de aptidão ao uso turístico estão apresentadas na Tabela 4.

Tabela 4. Áreas de cada classe de aptidão ao uso turístico

\begin{tabular}{|c|c|c|}
\hline $\begin{array}{c}\text { Classe de aptidão ao uso } \\
\text { turístico }\end{array}$ & $\begin{array}{c}\text { Área } \\
\left.\mathbf{( k m}^{2}\right)\end{array}$ & $\begin{array}{c}\text { Porcentagem da } \\
\text { área }\end{array}$ \\
\hline Baixa aptidão & 0,32 & $0,73 \%$ \\
\hline Média aptidão & 6,44 & $14,59 \%$ \\
\hline Alta aptidão & 32,28 & $73,15 \%$ \\
\hline Muito alta aptidão & 5,09 & $11,53 \%$ \\
\hline Total & $\mathbf{4 4 , 1 3}$ & $\mathbf{1 0 0 , 0 0 \%}$ \\
\hline
\end{tabular}

A maior parte do entorno da trilha tem alta aptidão ao uso turístico $(73,15 \%)$, sendo observadas também, regiões com aptidão muito alta $(11,53 \%)$. Boa parte deste resultado se deve à presença de declividade moderada (3-8\%) ao longo de $16 \mathrm{~km}$ da extensão da trilha $(16 \mathrm{~km})$. Esta porção é considerada, segundo modelo de Decanini (2001) para análise de oportunidade e restrição para alocação de trilhas eco turísticas, um caminho de média dificuldade, que exige cuidados leves para o manejo da erosão. Recebe destaque também, a proximidade das vias de acesso que contemplam o início e término da trilha e a presença de recursos hídricos ao longo da mesma. Apesar disso, existe carência de pontos de apoio ao longo do percurso, o que dificulta aos turistas terem local ideal de descanso, serviços sanitários, água potável e descarte correto de seus resíduos (Rangel, Botelho e Machado, 2017).

É importante observar que áreas com baixa e média aptidão ao uso turístico coincidem, em sua maioria, com áreas mais susceptíveis à erosão, que são justamente as regiões com maior declividade, próximas a paredões rochosos. Tais trechos 
demandam, com relação à implementação da trilha, uma maior atenção quanto à segurança dos turistas, uma vez que podem causar acidentes graves como queda ou escorregamento. Como medida preventiva, sugere-se que o traçado da trilha seja alterado no sentido Norte, afastando-se este trecho. Tal alteração se faz possível uma vez que a poucos metros dos paredões - atrativos turísticos importantes - existe uma região com alta aptidão ao uso turístico. Desse modo, os riscos de erosão da área seriam minimizados e concomitantemente haveria um aumento da segurança dos turistas.

Outro ponto associado ao traçado diz respeito ao planejamento da trilha em dimensões que impeçam a passagem de veículos. Além de ser um risco ao usuário recreacional da trilha, o automóvel pode aumentar as ameaças de contaminação ambiental por vazamento de líquidos, emissão de gases e deposição de resíduos (Vieira, Calliari e Oliveira, 2004; Arruda et al, 2019). O Plano de Manejo do PNSC (ICMBIO,
2005) alerta para o tráfego constante de veículos, pois provoca mortandade direta de indivíduos e desestruturação da habitats. Também contribui com o aumento dos focos de processos erosivos e de compactação dos solos nas proximidades das trilhas do alto da Casca D'Anta. Portanto, pensar a trilha para uso exclusivo de pedestres é fundamental para a promoção de seu uso sustentável.

A vegetação rasteira presente no bioma Cerrado, dentro da aptidão ao uso turístico, pode ser considerada uma força, pois é vista como um atrativo pela sua beleza cênica com características restritas ao território brasileiro (Bizerril, 2003; Nazar e Rodrigues, 2019). Associado a essa beleza cênica que o bioma Cerrado oferece, ao percorrer o trajeto da trilha, também se encontram atrativos turísticos como os Mirantes e a cachoeira Casca D’anta (Figura 4).

Tabela 5. Matriz SWOT - Resultados das potencialidades e fragilidades.

\begin{tabular}{|c|c|}
\hline Potencialidades & Fragilidades \\
\hline Forças & Fraquezas \\
\hline $\begin{array}{c}1 \text { - Presença de estradas (vias de acesso) nos pontos de início e } \\
\text { término da trilha. }\end{array}$ & $\begin{array}{c}1 \text { - Presença de relevo escarpado próximo aos dois últimos pontos } \\
\text { turísticos ( } 2^{\circ} \text { Mirante e Casca D'Anta). }\end{array}$ \\
\hline $\begin{array}{l}2 \text { - Vegetação rasteira predominante na trilha é favorável ao } \\
\text { ecoturismo. }\end{array}$ & 2 - Neossolo predominante favorável à erosão. \\
\hline 3 - Proximidade com os recursos hídricos. & 3 - Ausência de pontos de apoio ao longo da trilha. \\
\hline 4 - Proximidade a pontos turísticos. & 4 - Carência de educação ambiental dos visitantes. \\
\hline 5 - Predominância de inclinação suave ao longo da trilha. & 5 - Dificuldade de fiscalização. \\
\hline Oportunidades & Ameaças \\
\hline 1 - Barreira para passagem de veículos. & 1 - Descarte irregular de resíduos. \\
\hline 2 - Atrair investimento para região. & 2 - Risco de incêndios. \\
\hline 3 - Criação de empregos. & 3 - Alta suscetibilidade à compactação do solo. \\
\hline $\begin{array}{c}4 \text { - Desenvolvimento de Educação Ambiental e incentivo à } \\
\text { pesquisa científica. }\end{array}$ & 4 - Evasão de espécies endêmicas devido à degradação dos habitats. \\
\hline 5 - Sensibilização quanto à importância do Bioma Cerrado. & 5 - Aumento da coleta ilegal da fauna e flora. \\
\hline
\end{tabular}

Ademais, a trilha sugerida pode atuar positivamente na criação de empregos e de oportunidades de trabalho para as comunidades locais ao promover atividades fornecedoras de serviços de ecoturismo, gerando demandas que estimulem o desenvolvimento de empreendimentos em escala local, atraindo investimentos para a região e possibilitando o crescimento do ecoturismo (Trigo et al., 2005; Rech, Perello e Canto-Silva, 2018). Nesta vertente, um estudo de Andrade et al. (2016) aponta para o ecoturismo como um dos segmentos econômicos em alta na região do Parque Nacional Serra da Canastra, além de evidenciar que o planejamento das rotas turísticas é fundamental para fomentar empreendimento locais. Ainda, o mesmo autor classifica as trilhas já existentes no parque de acordo com a sua severidade, intensidade de esforço físico, condições do terreno e orientação no percurso, criando painéis 
interpretativos para cada uma das trilhas com informações relevantes para o turista. Desse modo, caso a proposição da trilha analisada se concretize, trabalhos como o de Andrade et al. (2016) se mostram de extrema importância, uma vez que geram informações fundamentais ao turista e evitam o uso indiscriminado da trilha

No contexto de implementação da trilha no Parque, a educação ambiental surge como uma oportunidade que pode ser aproveitada, assim como mencionado por Rocha et al. (2017). A utilização da trilha, enquanto prática ambiental, permite a sensibilização dos usuários quanto a importância do bioma ao transmitir conhecimentos através do contato físico, olfato, visão e sentimentos (Silva et al., 2012; Matos, Ferreira, Zampieron, 2017). A educação ambiental dentro deste cenário assume tamanha relevância que sua ausência pode indicar uma ameaça: a trilha pode sofrer com o descarte irregular de resíduos, coleta ilegal da fauna e flora, evasão de espécies nativas e com o aumento do risco de incêndio ilegal. (Cavalcante e Furtado, 2011)

Em suma, as forças, fraquezas, oportunidades e ameaças associadas a existência da trilha sugerida estão indicadas na Tabela 5.

\section{Conclusões}

A técnica da análise multicritério se mostrou bastante eficaz para a realização do estudo, uma vez que é rápida e de baixo custo para identificação das áreas mais propensas à erosão e na classificação da aptidão ao uso turístico, viabilizando, assim, a replicação da metodologia para a análise de outras trilhas ecoturísticas.

Mais de $80 \%$ da área estudada possui aptidão alta e muito alta ao uso turístico, mesmo possuindo solo suscetível à erosão.

As maiores potencialidades encontradas para o traçado proposto foram a proximidade de estradas e de recursos hídricos, facilitando o acesso do turismo, além de inclinação suave na maior parte do trecho. A implementação da trilha pode atrair maiores investimentos para a região, além de ser utilizada para atividades de educação e sensibilização ambiental.

Quando às fragilidades, destacaram-se o tipo de solo, favorável à erosão, um trecho de relevado escarpado que pode provocar acidentes, a ausência de pontos de apoio ao turista no decorrer da trilha, e a possibilidade de aumento, com o tráfego de turistas, do risco de incêndio, de evasão de espécies e do descarte irregular de resíduos no local.

Por fim, sugere-se que uma pequena mudança no traçado da trilha pode minimizar algumas de suas fragilidades, aumentando sua viabilidade de implementação.

\section{Agradecimentos}

Agradecemos a CAPES e ao PIBPOSUNIFAL pelo financiamento das bolsas de pósgraduação dos autores.

\section{Referências}

Adarme, M. O., Feitosa, R. Q., Happ, P. N., Almeida, C. A., Gomes, A. R, 2020. Evaluation of deep learning techniques for deforestation detection in the brazilin amazona and cerrado biomes from remote sensing imagery. Remote Sensing 12, 910.

Almeida, C. N. R., 2014. Estudo geoambiental da região da Serra da Canastra -MG: potencialidades e restrições ao uso turístico. Dissertação (Mestrado). São Paulo, Escola de Engenharia de São Carlos.

Andrade, B.S.; Melo, M.R.S.; Silva, M.H.S., 2019. Geoprocessamento aplicado à análise do uso do solo na área de proteção ambiental dos mananciais do córrego Lajeado, Campo Grande -MS. Sociedade e Território 31, 200-220.

Andrade, C. O. P., Carvalho, R. C. R., Godinho, R. F., Magri, R. A. F., 2016. Elaboração e aplicação de uma rota de trekking em uma área do Parque Nacional da Serra da Canastra. Revista Brasileira de Ecoturismo 9, 285-317.

Antunes, P. B., 2012. Direito Ambiental. 14 ${ }^{\mathrm{a}}$ ed. Editora Atlas, São Paulo.

Araujo, M. A. R., 2007. Unidade de Conservação no Brasil: da República à Gestão de Classe Mundial. $1^{\text {a }}$ ed. Editora SEGRAC, Belo Horizonte.

Arruda, B. S., Nascimento, A. P., Cordeiro, J., Therezo, P. E. A., Alvarenga, C. A., Cordeiro, J. L., 2019. Caracterização dos impactos desencadeados pelo ecoturismo na Cachoeira da Santa, Catas Altas (MG). Res. Soc. Dev. 3, 120.

Balmford, A., Green, J. M. H., Anderson, M., Beresford, J., Huangh, C., Naidoo, R., walpole, M., Manica, A., 2015. Walk on the Wild Side: Estimating the Global Magnitude of Visits to Protected Areas. PLOS Biology 13, 1-6. 
Bizerril, M. X. A., 2003. O Cerrado nos livros didáticos de geografia e ciências. Ciência hoje 32, 56-60.

BRASIL, 2000. Lei no 9.985 de 18 de julho.

Brooks, T.B, Fonseca, G. A. B., Rodrigues, Ana S. L, 2004. Species, Data, and Conservation Planning. Conservation Biology 18, 1682-1688.

Canto-silva, C. R., Silva, J. S., 2017. Panorama da visitação e da condução de visitantes em Parques brasileiros. Revista Brasileira de Pesquisa Turística 11, 365-386.

Cavalcante, M., Furtado, E. M., 2011. Políticas públicas de turismo em Unidades de Conservação. Mercator 10, 133-146.

Chang, H., Huang, W., 2006. Application of a quantification SWOT analytical method. Mathematical and computer modelling, 43, 158-169.

Crepani, E., Medeiros, J. S. de., 2001. Sensoriamento remoto e geoprocessamento aplicados ao zoneamento ecológico-econômico e ao ordenamento territorial. São José dos Campos: Inpe, 103. Disponível em: http://sap.ccst.inpe.br/artigos/CrepaneEtAl.pdf. Acesso em: 25 nov 2019.

Cuiabano, M. N., Neves, S. M. A. S., Nunes, M. C. M., Serafim, M. E., Neves, R. J., 2017. Vulnerabilidade ambiental à erosão hídrica na sub-bacia do Córrego do Guanabara/Reserva do Cabaçal-MT, Brasil. Geociências 36, 138-153.

Cullinane, T. C., Koontz, L., 2016. National Park visitors pending effects: Economic contributions to local communities, states, and the nation. Natural Resource Report. National Park Service, Fort Collins.

Cunha, A., Nóbrega, W., Kerlei, S., 2017. Instâncias de Governança e Turismo em Unidades de Conservação em Criação: Estudo de Caso do Parque Estadual dos Mangues do Potengi - RN. Revista Turismo e Desenvolvimento. 1, 599-610.

Decanini, M. M. S., 2001. SIG no planejamento de trilhas no Parque Estadual de Campos do Jordão. Revista Brasileira de Cartografia 1, 97110.

Ferreira, T. H. C., Chig, L. A., Favoro, E. G. P., Andrade, J. M., Oliveira, S. S., 2017. Estudo de caso: avaliação de impactos ambientais no Horto Florestal Tote Garcia em Cuiabá - Mato Grosso. Uniciências 21, 74-80.

Fiagbomeh, R. F., Bürger-Arndt, R., 2015. Prioritization of strategies for protected area management with local people using the hybrid
SWOT-AHP analysis: the case of Kakum conservation area, Gana. Management Science Letters 5, 457-470.

Filetto, F., Macedo, R. L. G., 2015. Desenvolvimento de indicadores de sustentabilidade para o ecoturismo em Unidades de Conservação. Revista Brasileira De Ecoturismo, 8, 11-30.

Françoso, R.D., Brandão, R., Nogueira, C.C., Salmona, Y.B.; Machado, R.B.; Colli, G.R., 2015. Habitat loss and the effectiveness of protected areas in the Cerrado Biodiversity Hotspot. Natureza e Conservação,13, 35-40.

Freire, P. M. O., Almeida, F. A. B., 2018. Ecoturismo, educação ambiental crítica e formação de sujeitos ecológicos: convergências e desafios. Revista Brasileira De Ecoturismo, 11, 561-587.

Freitas, D. A., Durães, A. F. S., Firmo, D. H. T., Pinho, N. B. de., Carvalho, L. R. de., 2019. Levantamento de dados de espécies florestais nativas do Cerrado: um meio para bancos de sementes implantados que permitem restauração e conservação de ecossistemas florestais. Brazilian Journal of Animal and Environmental Research 2, 1569-1583.

Giovanelli, J. G. R., Nobre, A. B., BacellarSchittini, A. E. F., Uehara-Prado, M., 2016. Demandas de monitoramento da biodiversidade: sistematização de informação para a gestão das unidades de conservação. Biodiversidade Brasileira 6, 4-17.

Gonçalves, H., Meneguzzo, I. S., Moro, R. S., 2019. Políticas públicas para a conservação do Bioma Cerrado no Estado do Paraná, Brasil. Terra Plural 13, 138-152.

Guerra, A. J. T., Fullen, M. A., Jorge, M. do C. O., Bezerra, J. F. R., Shokr, M. S., 2017. Slope Processes, Mass Movement and Soil Erosion: A Review. Pedosphere, 27, 27-41

Guerra, A., Reis, L. K., Borges, F. L. G., Ojeda, P. T. A., Pineda, D. A. M., Miranda, C. O., Maidana, D. P. F. L., Santos, T. M. R. D., Shibuya, P. S., Marques, M. C. M., Laurance, S. G. W., Garcia, L.C, 2020. Ecological restoration in Brazilian biomes: Identifying advances and gaps. Forest Ecology and Management, 458, 1-7.

Hesselbarth, W., Vachowsski, B., Davies, M. A., 2009. Manual de construção e Manutenção de Trilhas. Secretaria de Meio Ambiente, São Paulo.

Hockett, K. S., Marion, J. L., Leung, Y-F., 2017. The efficacy of combined educational and site 
management actions in reducing off-trail hiking in an urban-proximate protected area. Journal of Environmental Management, 203, 17-28.

Huhtala, M., Kajala, L., Vatanen, E., 2010. Local economic impacts of national park visitors' spending: The development process of an estimation method. Working Papers of the Finnish Forest Research Institute 149, 1-20.

Hummel, C., Poursanidis, D., Orenstein, D., Elliott, M., Adamescu, M. C., Cazacu, C., Ziv G., Chrysoulakis, N., Van Der Meer, J.; Hummel, H., 2019. Protected area management: Fusion and confusion with the ecosystem services approach. Science ofthe total Environment 651, 2432-2443.

IBAMA. Instituto Brasileiro do Meio Ambiente e dos Recursos Naturais Renováveis, 2005. Plano de manejo do Parque Nacional da Serra da Canastra.

Klink, C. A., Machado, R. B., 2005. A conservação do Cerrado brasileiro. Megadiversidade 1, 147155.

Lemes, P., Loyola, R., 2014. Mudanças climáticas e prioridades para a conservação da biodiversidade. Revista de Biologia Neotropical, 11, 47-57.

Lobo, A. C., Simão, L. L., 2011. Manual de Monitoramento e Gestão dos Impactos da Visitação em Unidades de Conservação, $1^{\mathrm{a}}$ ed. Fundação Florestal, WWF, São Paulo.

Locatelli, B., Imbach, P.; Wunder, S., 2013. Synergies and trade-offs between ecosystem services in Costa Rica. Environmental Conservation 41, 27-36.

Manetta, B. A. R.; Barroso, B. R.; Lipiani, G.O.; Azevedo, J. B.; Arrais, T. C.; Nunes, T. E. S., 2015. Unidades de Conservação. Engenharias Online 1, 1-10.

Matos, B. C. S., Ferreira, M. P. S., Zampieron, S. L. M., 2017. Formação de agentes disseminadores do processo de educação ambiental para unidades de conservação, com ênfase no Parque Nacional da Serra da Canastra, Minas Gerais. Em Extensão 16, 97-114.

Matos, B. C. S., Ferreira, M. P. S., Zampieron, S. L. M., 2017. Formação de agentes disseminadores do processo de educação ambiental para unidades de conservação, com ênfase no Parque Nacional da Serra da Canastra, Minas Gerais. Em Extensão 16, 97-114.

Messias, C.G., Ferreira, M. C., 2017. Aplicação do método de classificação contínua Fuzzy para o mapeamento da fragilidade do terreno em relação à ocorrência de ravinas no Parque Nacional da Serra da Cantra. Raega 39, 111 127.

Mihalic, T., 2016., Sustainable-responsible tourism discourse - Towards' responsustable' tourism. Journal of Cleaner Production 111, 461-470.

Montaño, M., 2002. Os recursos hídricos e o zoneamento ambiental: o caso do município de São Carlos (SP). Dissertação (Mestrado). São Carlos, Universidade de São Paulo.

Muruthi, P., 2006. The Process of Preparing a General Management Plan for a Protected Area. AWF WorkingPapers, 1-11.

Myers, N.; Mittermeier, R. A.; Mittermeier, C. G.; Fonseca, G. A. B.; Kent, J., 2000. Biodiversityhotspots for conservationpriorities. Nature 403, 853-858.

Nascimento, C. A.; Canto-Silva, C. R.; Melo, I. B. M.; Marques, S. C. M., 2016. A regulamentação da atividade de condução de visitantes nos Sistemas Estaduais de Unidades de Conservação do Brasil. Rev. Bras. Pesq. Tur. 10, 516-532.

Nazar, T. I. S., Rodrigues, S. C., 2019. Relevo do Chapadão do Diamante, Serra da Canastra/MG, Brasil: compartimentação e análise a partir dos aspectos geomorfométricos. Revista Brasileira de Geomorfologia 20, 69-88.

Neto, D.S.; Whitaker, D. S. A.; Vasconcelos, V. A.; 2018. Educação em Unidades de Conservação: Luta por direitos e direito à luta. Revista de Educação Popular. 17, 51-67.

Oliveira, F. B., Oliveira, C. H. R. de., Lima, J. S. de S., Miranda, M. R., Filho, R. B. R., Turbay, E. R. M. G., Ferraz, F., 2014. Definição de áreas prioritárias ao uso público no parque estadual da Cachoeira da Fumaça - ES, utilizando geoprocessamento. Rev. Árvore 38, 1027-1036.

Oliveira, F. S., 2019. Turismo sustentável e riqueza social: bases para o desenvolvimento da economia local. Revista Gestão e Desenvolvimento 16, 03-28.

Oliveira, L. R. C. N. de., Barros, M. I. A. de., Buchianeri, V. C. (Org.)., 2008. Manual de Construção e Manutenção de Trilhas. São Paulo.

Park, D., Kim, J., Kim, W.G., Park, H., 2019. Does distance matter? Examining the distance effect on tourists' multi-attraction travel behaviors. Journal of Travel \& Tourism Marketing, 36, 692-709.

Prates, A. P. L., De Azevedo I. M., 2015. Conservação da biodiversidade e políticas 
públicas para as áreas protegidas no Brasil: desafios e tendências da origem da CDB às metas de Aichi. Revista Brasileira de Políticas Públicas 5, 27-57.

Rangel, L, A.; Botelho, L.; Machado, R. G., 2017. Análise Ambiental da trilha Sahy-Rubião no Parque Estadual Cinhambebe emMangaratiba (RJ) por meio de um Protocolo de Avalização Rápida. Geo UERJ 1, 391-418.

Rech, I. F., Perello, L. F. C., Canto-Silva, C. R., 2018. Panorama do uso público em Parques Estaduais do Rio Grande do Sul. Revista Brasileira de Ecoturismo 10, 919-937.

Reis, A. F., Queiroz, O. O. T. M. M., 2017. Visitação no parque estadual da Cantareira (PEC): Reflexões sobre o uso recreativo de uma Unidade de Conservação (UC). Revista de Turismo Contemporâneo 5, 42-60.

Resende, F. M., 2018. Planejamento para conservação de serviços ecossistêmicos no Cerrado. Tese (Doutorado). Goiânia, Universidade Federal de Goiás, .

Riondet-Costa, D. R. T., Botezelli, L., Silva, B. G., Farias, O. L. M, 2013. Zonas de amortecimento em Unidades de Conservação: Levantamento Legal e Comparativo das Normas nos Estados de Minas Gerais, Rio de Janeiro e São Paulo. Desenvolvimento e Meio Ambiente 26, 57-70.

Rocha, I. L. de O., Carvalho, R. de C. R., Rocha, W. W., Reis, M. J., Pires, B. S., 2018. Avaliação da aplicação de carga antrópica em uma trilha no Parque Nacional da Serra da Canastra (Estado de Minas Gerais, Brasil). Revista Brasileira de Gestão Ambiental e Sustentabilidade 5,291-300.

Rocha, M., Pin, J. R. O., Goés, Y. C. B., Rodrigues, L. A., 2017. O potencial das trilhas ecológicas como instrumento de sensibilização ambiental: o caso do Parque Nacional da Tijuca. Revista multidisciplinar de ensino 6, 81-96.

Rodrigues, A. S., COLLARES, A. C. Z. B., 2017. Proposta de uso sustentável na Bacia Hidrográfica do Ribeirão Formiga em Delfinópolis-MG. Sociedade \& Natureza 29, 337-350.

Rodrigues, E. N. L., Milton de S. M. J., Patrícia, E. S. R., Ricardo, O, 2015. Diversity, composition and phenology of araneid orb-weavers (Araneae, Araneidae) associated with riparian forests in Southern Brazil. Iheríngia 105, 53-61

Sano, E. E., Rodrigues, A. A., Martins, E. S., Bettiol, G. M., Bustamante, M. M. C., Bezerra, A. S., Couto JR., A. F., Vasconcelos, V., Schüler, J., Bolfe, E. L., 2019. Cerrado ecoregions: A spatial framework to assess and prioritize Brazilian savanna environmental diversity for conservation. Journal of Environmental Management, 232, 818-828.

Santos, W. A., Almeida, A. Q., Cruz, J. F., Mello, A. A., Santos, R.B., Loureiro, D.C., 2017. Conflito de uso da terra em áreas de preservação permanente da bacia do rio Piauitinga, Sergipe, Brasil. Rev.Cienc. Agrar. 60, 19-24.

Saraiva, V. I. C.; Silva, A. S. da.; Santos, J. P. C. dos, 2016. Uso do mapa de solos como subsídio para definição de áreas de suscetibilidade à erosão na Bacia Hidrográfica São João, Lagos e Una. Geo Uerj, Rio de Janeiro, 29, 354-373.

Scolozzi, R., Schirpke, U., Morri, E., D'amato, D., Santolini, R., 2014. Ecosystem services-based SWOT analysis of protected areas for conservation strategies. Journal Environmental Management. 146, 543-551.

Silva, M. M., Netto, T. A., Azevedo, L. F., Scarton, L. P., Hilig, C., 2012. Trilha Ecológica como prática de Educação Ambiental. Revista Eletrônica em Gestão, Educação e Tecnologia Ambiental 5, 705-719.

Silva, R.F. T. da., 2015. Manual de Direito Ambiental. 5. ed. JusPodivm, Salvador.

Souza, T. do V. S. B., Thapa, B., Rodrigues, C. G. de O., Imori, D., 2017. Contribuições do Turismo em Unidades de Conservação Federais para a Economia Brasileira. ICMBio, Brasília.

Teixeira, P. R., Michelin, R. L., 2017. Mapeamento dos indicadores de impacto ambiental e manejo na trilha do Parque Nacional do Viruá-Roraim. Turismo - Visão e ação 19, 270-291.

Tomczyk, A. M., Ewertowski, M., 2013. Planning of recreational trails in protect areas: application of regression tree analysis and geographic information systems. Applied Geography, 40, 339-351.

Trigo, L. G. G., Panosso Netto, A., Carvalho, M. A., Pires, P. dos S., 2005. Análises regionais e globais do turismo brasileiro $1^{\mathrm{a}}$ Ed. Roca, São Paulo.

Trindade, S. P., Rodrigues, R. de Á., 2016. Uso do solo na microbacia do Ribeirão Samambaia e sua relação com a suscetibilidade à erosão laminar. Revista Geografia Acadêmica 10, 163 181.

Vallejo, L. R., 2013. Uso público em áreas protegidas: atores, impactos, diretrizes de planejamento e gestão. Revista Eletrônica Uso Público em Unidades de Conservação 1, 13-26.

Vieira, H., Calliari, L. J., Oliveira, G. P. de., 2004. O estudo do impacto da circulação de veículos 
Revista Brasileira de Geografia Física v.13 .n. 06. (2020) .2978-2991.

em praias arenosas através de parâmetros físicos: um estudo de caso. ENGEVISTA. 6, 5463.

Xu, W., Xiao, Y., Zhang, J., Yang, W., Zhang, L., Hull, V., Wang, Z., Zheng, H., Liu, J., Polasky, S., Jiang, L., Xiao, Y., Shi, X., Rao, E., Lu, F.,
Wang, X., Dally, G. C., Ouyang, Z., 2017. Strengthening protected areas for biodiversity and ecosystem services in China. Proceedings of the National Academy of Sciences. 114, 1601-1606. 